\title{
Prehospital triage and direct transport of patients with ST-elevation myocardial infarction to primary percutaneous coronary intervention centres: a systematic review and meta-analysis
}

\author{
Steven C. Brooks, MD, MHSc; ${ }^{* \dagger \ddagger}$ Katherine S. Allan, BSc, MASc; ${ }^{*} \S$ Michelle Welsford, BSc, MD; \\ P. Richard Verbeek, MD; ${ }^{\dagger * * *}$ Hans-Richard Arntz, MD, PhD; ${ }^{\dagger \dagger}$ Laurie J. Morrison, MD, MSc ${ }^{* \ddagger}$
}

See related articles on pages 423 And 473

\section{ABSTRACT}

Objective: Percutaneous coronary intervention (PCI) appears to be superior to in-hospital fibrinolysis for most patients with ST-elevation myocardial infarction (STEMI). However, few hospitals have $\mathrm{PCl}$ capability. The optimal prehospital strategy for facilitating rapid coronary reperfusion in STEMI patients is unclear. We sought to determine whether direct transport of adult STEMI patients by emergency medical services to primary $\mathrm{PCl}$ centres improves 30 -day all-cause mortality when compared with a strategy of transportation to the closest hospital.

Methods: We systematically searched MEDLINE, EMBASE, Cochrane "CENTRAL" database (1980-July 2007) and several other electronic databases. Two authors independently assessed citations for relevance. Two authors independently abstracted data from included studies. We included studies that, 1) transported patients directly to a $\mathrm{PCl}$-capable centre for primary $\mathrm{PCl}, 2$ ) had a control group that was transported to the closest hospital and 3) reported outcomes of treatment time intervals, all-cause mortality, reinfarction rate, stroke rate or the frequency of cardiogenic shock. We used a random effects model to provide pooled estimates of relative risk (RR) when data allowed.

Results: We identified 2264 citations with the search. Five studies, including 980 STEMI patients, met inclusion criteria, and were clinically heterogeneous and of variable quality. Most studies were European (3/5) and involved physician out-of-hospital care providers. There was a trend toward increased survival with direct transport to primary $\mathrm{PCl}$ but this was not statistically significant (RR $0.51,95 \%$ confidence interval $[\mathrm{Cl}]$ 0.24-1.10). One study reported nonsignificant reductions in reinfarction ( $\mathrm{RR} 0.43,95 \% \mathrm{Cl} 0.11-1.60$ ) and stroke (RR $0.33,95 \% \mathrm{Cl} 0.01-8.06$ ) with direct transport for primary $\mathrm{PCl}$.

Conclusion: There is insufficient evidence to support the effectiveness of direct transport of patients with STEMI for primary $\mathrm{PCl}$ when compared with transportation to the closest hospital.

Keywords: ST-elevation myocardial infarction, emergency medical services, EMS, reperfusion strategies, primary percutaneous coronary intervention, $\mathrm{PCl}$

\section{RÉSUMÉ}

Objectif : L'intervention coronarienne percutanée (ICP) semble donner de meilleurs résultats que la fibrinolyse en milieu hospitalier pour la plupart des patients victimes d'un infarctus du myocarde avec sus-décalage du segment ST (STEMI). Or, peu d'hôpitaux peuvent pratiquer I'ICP. La meilleure stratégie extrahospitalière pour faciliter la reperfusion coronarienne précoce chez ces patients n'est pas claire. Nous avons cherché à déterminer si le transport direct des adultes victimes d'un STEMI par les services médicaux d'urgence à des centres d'ICP primaires (ICPP) réduit davantage le taux de mortalité toutes causes confondues dans les 30 jours par rapport au transport à I'hôpital le plus proche.

Méthodes : Nous avons interrogé systématiquement plusieurs bases de données électroniques, dont MEDLINE, EMBASE, le Registre central Cochrane des essais contrôlés (CENTRAL) (1980 à juillet 2007). Deux des auteurs ont évalué séparément

From the *Rescu, Keenan Research Centre, Li Ka Shing Knowledge Institute, St. Michael's Hospital, Toronto, Ont., †Program for Trauma, Emergency and Critical Care, Department of Emergency Services, Sunnybrook Health Sciences Centre, Toronto, Ont., the ¥Division of Emergency Medicine, Department of Medicine, University of Toronto, Toronto, Ont., §Electrophysiology Research, Department of Cardiology, St. Michael's Hospital, Toronto, Ont., the IDepartment of Medicine, Division of Emergency Medicine, McMaster University, Hamilton, Ont., **Sunnybrook Osler Centre for Prehospital Care, Toronto, Ont., and the ††Department of Cardiopulmonology, Charité, Campus Benjamin Franklin, Berlin, Germany

Submitted Jun. 2, 2008; Revised Nov. 26, 2008; Accepted Jan. 6, 2009

This article has been peer reviewed.

CJEM 2009;11(5):481-92 
la pertinence des citations. Deux autres auteurs ont résumé indépendamment les données des études. Nous avons inclus les études qui : 1) portaient sur les patients transportés directement vers un centre d'ICP pour la réalisation immédiate d'une ICPP; 2) comprenaient un groupe témoin ayant été transporté à I'hôpital le plus proche; et 3) ont fait état des résultats relatifs aux délais avant le traitement, à la mortalité toutes causes confondues, au taux de récidive d'infarctus, au taux d'accident vasculaire cérébral ( $A V C$ ), ou à la fréquence de choc cardiogénique. Nous avons utilisé un modèle à effets aléatoires pour fournir une estimation des données regroupées du risque relatif ( $R R$ ) lorsque les données le permettaient.

Résultats : Notre recherche des bases de données a permis de repérer 2264 citations. Cinq études, comprenant 980 patients avec STEMI, répondaient aux critères d'inclusion et étaient cliniquement hétérogènes et de qualité variable. La plupart des études étaient européennes (3/5) et mettaient à contribution des médecins extrahospitaliers. Nous avons noté une tendance à la hausse du taux de survie lorsqu'il y avait transport direct à un centre d'ICPP, mais elle n'était pas statistiquement significative (RR à 0,51 , intervalle de confiance [IC] à $95 \%$ de 0,24 à 1,10). Une étude faisait état d'une réduction non importante de récidive d'infarctus (RR à 0,43; IC à $95 \%$ de 0,11 à 1,60 ) et d'AVC (RR à 0,33 ; IC à $95 \%$ de 0,01 à 8,06 ) lorsque le patient avait été transporté directement à un centre d'ICPP.

Conclusion : II n'y a pas suffisamment de preuves pour appuyer l'efficacité du transport direct des patients avec STEMI à un centre en vue d'une ICPP par rapport au transport vers l'hôpital le plus proche.

\section{INTRODUCTION}

\section{Background and importance}

Each year, diseases of the heart cause approximately 50000 deaths in Canada ${ }^{1}$ and acute myocardial infarction (AMI) accounts for a large proportion of these. ${ }^{2}$ A recent report from the Cardiac Care Network of Ontario estimated that 20000 people were admitted to hospital for AMI in that province during the 2000/01 fiscal year, and more than 6500 of those patients were diagnosed with ST-elevation acute myocardial infarction (STEMI). ${ }^{3}$ Approximately $40 \%$ of patients with myocardial infarction (MI) are initially cared for and transported by emergency medical services (EMS). ${ }^{4}$ Controversy exists about how EMS systems should facilitate timely coronary reperfusion in STEMI patients ${ }^{5,6}$ and significant variation in practice is evident. ${ }^{4}$

Primary percutaneous coronary intervention (PCI) appears to be superior to in-hospital fibrinolysis for most patients with STEMI. ${ }^{7-9}$ However, most North American EMS protocols for chest pain involve transportation of patients to the closest hospital, most of which do not have PCI facilities. ${ }^{10,11}$ As defined in the 2004 STEMI guidelines by the American Heart Association and by the American College of Cardiology, ${ }^{12}$ skilled PCI facilities include interventional cardiologist operators who perform more than 75 primary PCI cases per year, and catheterization laboratory support team members who experience more than 36 primary PCI cases per year. Patient outcomes have been found to be associated with operator and facility volume. ${ }^{12}$

Urgent transfer of patients from community hospitals to primary PCI facilities is one potential method of improving access to primary PCI. However, data from the
National Registry of Myocardial Infarction in the United States suggest that interhospital transfer delays are excessive and may limit the feasibility of this strategy in many North American communities. ${ }^{8,13}$ This registry has demonstrated a median time from presentation at the first hospital to PCI at the second hospital of 180 minutes, ${ }^{13}$ which greatly exceeds the current recommendations for 90-minute medical contact-to-balloon interval. . $^{12,14,15}$

Another potential solution is a strategy of EMS personnel triage of STEMI patients directly to centres capable of PCI, bypassing closer non-PCI centres as necessary. ${ }^{16-22}$ The American Heart Association, in their 2005 Guidelines for Emergency Cardiovascular Care and Cardiopulmonary Resuscitation, was unable to recommend this strategy because of inadequate evidence. ${ }^{14,15}$ The ideal strategy for patients who are diagnosed with STEMI by emergency care providers in the prehospital setting remains unclear.

\section{Goals of this investigation}

We sought to determine whether direct transport to primary PCI centres improves 30-day mortality when compared with the standard strategy of transportation to the closest hospital for patients diagnosed with STEMI by prehospital emergency care providers.

\section{METHODS}

\section{Study design}

We performed a systematic review and meta-analysis of the world literature on this topic. We followed the Metaanalysis of Observational Studies in Epidemiology Group (MOOSE) guidelines for reporting our study. ${ }^{23}$ 


\section{Criteria for considering studies for review}

Studies considered for inclusion in the review were randomized controlled trials, quasi-randomized controlled trials, before-after studies and comparative cohort studies. Studies were included only if they reported data on adults (> 18 yr) who were diagnosed with acute STEMI, experienced chest pain for less than 12 hours and were identified by EMS personnel in the prehospital environment. There were no restrictions on the type of EMS system including personnel qualifications or crew configuration. The criterion for the treatment group intervention was that 12-lead prehospital electrocardiography (ECG) was used by EMS personnel to identify STEMI, followed by direct transportation from the scene to an interventional centre for primary PCI. Acceptable comparison groups included patients with STEMI who were identified through a 12-lead prehospital ECG and who received subsequent transportation to the nearest available emergency department (ED) with or without the administration of a prehospital fibrinolytic. Studies needed to report at least 1 outcome of all-cause mortality, reinfarction rate, stroke rate, the occurrence of cardiogenic shock or treatment time intervals including symptom onset to intervention, 911 call to intervention or medical contact to intervention. Intervention time was defined as either the time to needle insertion for fibrinolysis or the time to balloon inflation for PCI. Abstract-only publications were excluded.

\section{Search strategy}

We searched the following electronic databases: OVID MEDLINE (1980-July 2007), OVID EMBASE (1980July 2007), Cochrane "CENTRAL" database of randomized studies (Cochrane Library Wiley Interscience, 1980-July 2007), Web of Science (1980-July 2007), CINAHL on EBSCO (1980-September 2006), OVID HealthStar (1980-September 2006), Proquest Digital Dissertations (1980-September 2006), the NIH CRISP database (1980-September 2006), and clinicaltrials.gov (Jul. 18, 2007). We used modified components of the Cochrane Collaboration Prehospital and Emergency Health Field search strategy. ${ }^{24}$ Key search terms included "emergency medical services," "emergency medical technicians," "emergency medicine," "ambulances," "air ambulances," "allied health personnel," "prehospital," "paramedic," "myocardial infarction," "acute coronary syndrome," "chest pain," "transportation of patients," "patient transfer," "angioplasty," "heart catheterization," "percutaneous coronary intervention" and "primary angioplasty," in addition to several acronyms (e.g., STEMI) and synonyms for these terms. The full OVID MEDLINE search strategy can be seen in Table 1 . There were no restrictions on language of publication.

We hand searched the references of included studies and we attempted contact with the principle authors of included studies for knowledge of relevant studies.

\section{Selection of studies}

Two investigators (S.C.B. and K.S.A.) reviewed all English citations independently in a hierarchical manner. They were blinded to author, institutional affiliation, source journal and year of publication. Titles classified as "include" or "indeterminate" by at least 1 of the investigators were included in the next iteration of review by abstract. Similarly, we identified full articles for review. Disagreements during the full-article review were resolved by consensus between the 2 authors. Interrater reliability for each stage of the review process for inclusion was quantified using a $\kappa$ statistic. An international network of 20 volunteer translators was established to review non-English studies for relevance. The reviewers of non-English articles were not blinded. The volunteers were all health care providers or academic professionals identified through personal contacts of the first author (S.C.B.). In a similar manner to the English reviewers, the reviewers of non-English articles were instructed on the purpose of the systematic review, the inclusion and exclusion criteria and the use of the data form.

\section{Outcome measures}

The primary outcome measure for the review was determined a priori to be 30-day all-cause mortality. Based on limited data discovered with the review, a post hoc combination of in-hospital or 30-day mortality was defined as "short-term mortality" and used as the primary outcome. Secondary outcomes, determined a priori, included reinfarction, stroke and cardiogenic shock at 30 days, as well as clinically relevant time intervals including symptom onset to intervention (either time to needle or time to balloon), medical contact to intervention and EMS on-scene time.

\section{Data extraction and analysis}

Two investigators (M.W. and L.J.M.) abstracted data independently on the features of study design, interven- 
tion and control conditions, patient characteristics and reported outcomes. Data abstraction was standardized between the 2 investigators by using a common data abstraction form that was developed a priori and subject to pilot testing. The quality of the included studies was evaluated independently by 2 investigators (S.C.B. and P.R.V.) using a modified version of the Thomas Quality Assessment Tool for Quantitative Studies. ${ }^{25}$ Reviewers for both data abstraction and quality assessment were blinded to source institution, journal, date of publication and author. Disagreements between investigators for each process were resolved by consensus.

The clinical heterogeneity of included trials was explored qualitatively with a detailed examination of study characteristics. The $\chi^{2}$ test of homogeneity was used with a significance cut-off of 0.10 to test for statistical

\begin{tabular}{|c|c|c|c|}
\hline Line no. & Search term & Line no. & Search term \\
\hline 1 & exp Emergency Medical Services & \multirow[t]{2}{*}{32} & \multirow{2}{*}{$\begin{array}{l}1 \text { or } 2 \text { or } 3 \text { or } 4 \text { or } 5 \text { or } 6 \text { or } 7 \text { or } 8 \text { or } 9 \text { or } 10 \text { or } 11 \text { or } 12 \\
\text { or } 13 \text { or } 14 \text { or } 15 \text { or } 16 \text { or } 17 \text { or } 18 \text { or } 19 \text { or } 20 \text { or } 21 \text { or } \\
22 \text { or } 23 \text { or } 24 \text { or } 25 \text { or } 26 \text { or } 27 \text { or } 28 \text { or } 29 \text { or } 30 \text { or } 31\end{array}$} \\
\hline 2 & exp Emergency Medical Technicians & & \\
\hline 3 & exp Emergency Medicine & 33 & exp Myocardial Infarction/ \\
\hline 4 & exp Ambulances & 34 & exp Chest Pain/ \\
\hline 5 & exp Air Ambulances & 35 & exp Electrocardiography/ \\
\hline 6 & $\exp$ First Aid & 36 & exp Coronary Disease/ \\
\hline 7 & exp Military Medicine & 37 & exp Angina, Unstable/ \\
\hline 8 & $\begin{array}{l}\text { exp Emergency Medical Service Communication } \\
\text { Systems }\end{array}$ & 38 & myocardial infarct\$.mp. \\
\hline 9 & exp Allied Health Personnel & 39 & AMI.mp. \\
\hline 10 & prehospital.mp. & 40 & Ml.mp. \\
\hline 11 & pre-hospital.mp. & 41 & STEMI.mp. \\
\hline 12 & paramedic\$.mp. & 42 & acute coronary syndrome\$.mp. \\
\hline 13 & ambulance\$.mp. & 43 & acs.mp. \\
\hline 14 & out-of-hospital.mp. & 44 & ST-segment elevation.mp. \\
\hline 15 & out of hospital.mp. & 45 & ST-elevation.mp. \\
\hline 16 & EMS.mp. & 46 & chest pain.mp. \\
\hline 17 & EHS.mp. & 47 & $\begin{array}{l}33 \text { or } 34 \text { or } 35 \text { or } 36 \text { or } 37 \text { or } 38 \text { or } 39 \text { or } 40 \text { or } 41 \text { or } 42 \\
\text { or } 43 \text { or } 44 \text { or } 45 \text { or } 46\end{array}$ \\
\hline 18 & EMT.mp. & 48 & exp Angioplasty/ \\
\hline 19 & emergency services.mp. & 49 & exp Angioplasty, Transluminal, Percutaneous Coronary \\
\hline 20 & emergency medical service\$.mp. & 50 & exp Balloon Dilatation \\
\hline 21 & emergency technician\$.mp. & 51 & exp Heart Catheterization \\
\hline 22 & emergency practitioner\$.mp. & 52 & angioplasty.mp. \\
\hline 23 & emergency dispatch\$.mp. & 53 & percutaneous coronary intervention\$.mp. \\
\hline 24 & emergency despatch\$.mp. & 54 & $\mathrm{PCl} . \mathrm{mp}$ \\
\hline 25 & first responder\$.mp. & 55 & PTCA.mp. \\
\hline 26 & emergency rescue $\$ . m p$. & 56 & primary angioplasty.mp. \\
\hline 27 & emergency triage.mp. & 57 & percutaneous transluminal coronary angioplasty.mp. \\
\hline 28 & exp "Transportation of Patients" & 58 & primary coronary angioplasty.mp. \\
\hline 29 & on-scene.mp. & 59 & 48 or 49 or 50 or 51 or 52 or 53 or 54 or 55 or 56 or 57 \\
\hline 30 & on scene.mp. & & or 58 \\
\hline 31 & exp Patient Transfer/ & 60 & 32 and 47 and 59 \\
\hline $\begin{array}{l}\$=\text { trunce } \\
\text { syndrome } \\
\text { term and } \\
\text { title, abstr } \\
\text { elevation }\end{array}$ & $\begin{array}{l}\text { conceptually narrower terms within the } \mathrm{OVID} \text { medical subject } \mathrm{h} \\
\text { medical subject headings of articles); } \mathrm{PCl}=\text { percutaneous coror } \\
\text { ardial infarction. }\end{array}$ & $\begin{array}{l}\text { ieves all ar } \\
\text { gency hea } \\
=\text { myocar } \\
\text { n: PTCA }=\end{array}$ & $\begin{array}{l}\text { with this particular medical subject heading); acs = acute coronary } \\
\text { revices; EMT = emergency medical technician; exp = explode (searches for } \\
\text { ffarction; } m p=\text { textword search (searches for the word or words in the } \\
\text { utaneous transluminal coronary angioplasty; STEMI = ST-segment }\end{array}$ \\
\hline
\end{tabular}


heterogeneity. For all other hypothesis testing, a significance cut-off of 0.05 was used. The $I^{2}$ statistic was used to quantify statistical heterogeneity and determine the appropriateness of pooling results across studies. Studies were not pooled if the $I^{2}$ was $>50 \%$ indicating significant statistical heterogeneity. We used the DerSimonianLaird method (i.e., the random effects model) to provide pooled estimates of relative risk when the data allowed. Pooled estimates and forest plots were generated using Review Manager 4.2.10 (The Cochrane Collaboration).

\section{RESULTS}

\section{Trial flow}

The original comprehensive search identified 2264 citations published in 14 languages (Fig. 1). Ninety-eight full articles that were not published in English were reviewed. Five studies met all inclusion criteria and were included in the review. ${ }^{26-30}$ Interrater reliability for each stage of the review process for inclusion was quantified using a $\kappa$ statistic. The $\kappa$ was 0.55 for titles, 0.68 for abstracts and 0.92 for full articles. One author (S.C.B.) completed an updated search of MEDLINE, EMBASE and the Cochrane library up to May 2008 and no additional relevant studies were identified.

\section{Study characteristics}

Table 2 outlines the characteristics of the 5 included studies, which include a total of 980 patients. There were 2 randomized controlled trials, ${ }^{26,29} 2$ prospective observational studies with concurrent controls ${ }^{28,30}$ and 1 prospective observational study with a historical control group..$^{27}$ Three of the studies occurred in European EMS systems with ambulance medical doctors as the primary prehospital care provider. ${ }^{28-30}$ The other 2 studies were Canadian. ${ }^{26,27}$ Detailed descriptions of prehospital diagnostic techniques and the process of catheterization laboratory activation were lacking. Prehospital ECG interpretation was not described in one study, ${ }^{26}$ performed by the ambulance physician in 2 studies, ${ }^{28,29}$ by computer with ambulance nurse confirmation in one study, ${ }^{30}$ and by paramedic in one study. ${ }^{27}$ Two studies reported that the EMS personnel directly activated the catheterization laboratory, ${ }^{27,30}$ whereas the process of activation was unclear in the others.

The method of allocating patients to the intervention or control group varied. The 2 observational studies with concurrent control groups used convenience methods or patient clinical features to determine group allocation. For example, in the Terkelsen and colleagues study, ${ }^{28}$ only patients cared for by an ambulance crew which included a physician were allocated to the PCI arm of the study. In the van Bavel and colleagues study, ${ }^{30}$ group allocation was determined by the degree of STsegment elevation on the prehospital ECG. Quality varied considerably across the included studies (Table 3).

\section{Quantitative data synthesis}

Four studies reported short-term mortality ${ }^{27-30}$ (Fig. 2).

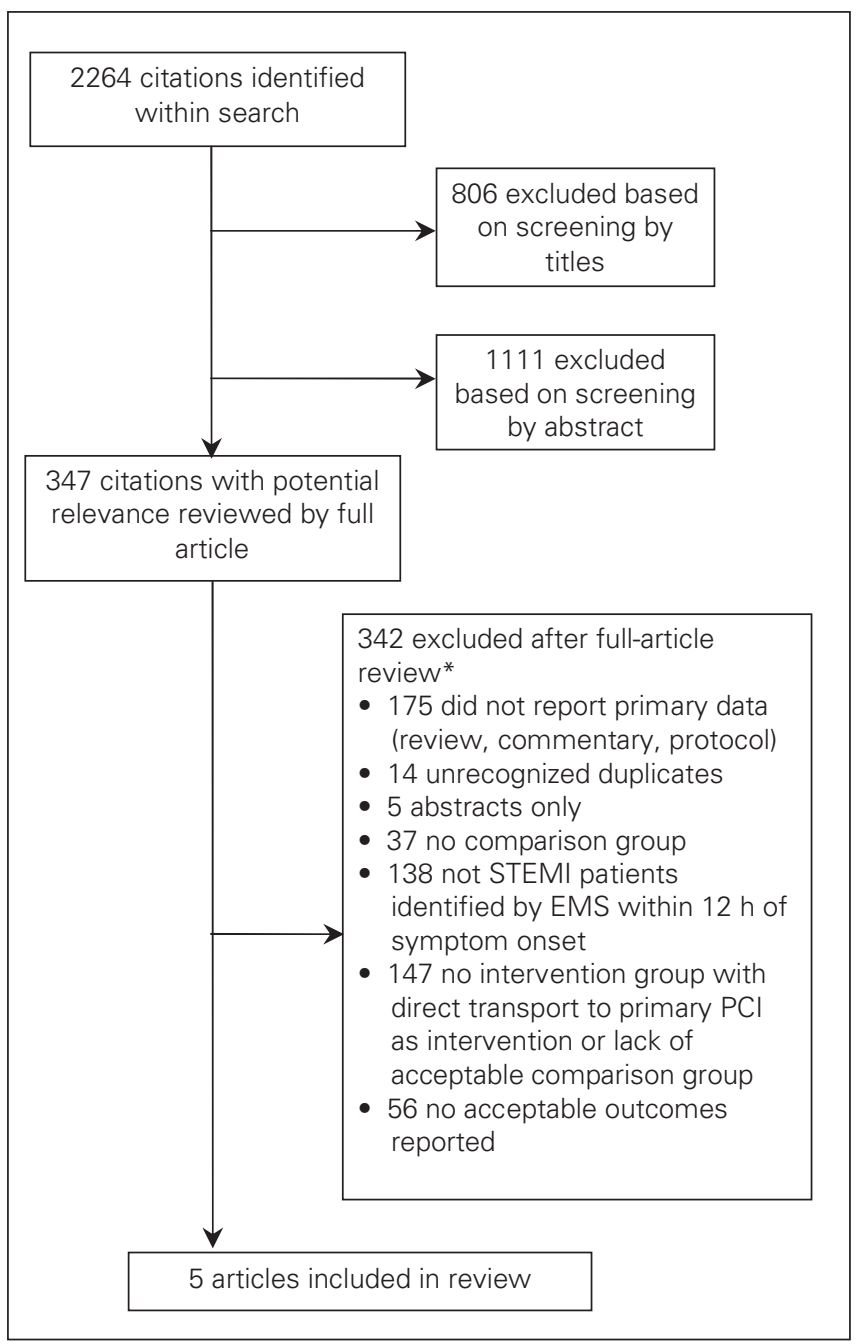

Fig. 1. Trial flow. After review of 2264 citations by title and abstract, 347 were considered to be potentially relevant. After review by full article, 342 were excluded for various reasons. Five were found to meet criteria for inclusion in the review. $\mathrm{EMS}=$ emergency medical services; $\mathrm{PCl}=$ percutaneous coronary intervention; STEMI = ST-elevation myocardial infarction. ${ }^{*}$ Component counts do not sum to total number excluded because many articles had multiple reasons for exclusion. 
There was no evidence of statistical heterogeneity among these 4 studies $\left(\chi^{2}=2.77, d f=3, p=0.43\right.$ and $\left.I^{2}=0 \%\right)$. The pooled relative risk (RR) for short-term mortality demonstrates a trend toward reduction with direct transport for primary PCI, but did not reach statistical significance (RR 0.51, 95\% confidence interval [CI] 0.24-1.10). One study ${ }^{29}$ demonstrated reductions in the rate of reinfarction (RR $0.43,95 \%$ CI $0.11-1.60)$ and stroke (RR $0.33,95 \%$ CI $0.01-8.06$ ) at 30 days, which were not statistically significant. None of the included studies reported rates of cardiogenic shock. Clinical outcome data from the Armstrong study ${ }^{26}$ could not be included in the pooled analysis because published data were for the entire study population, which included some patients initially assessed in the ED. Prehospital subgroup data were requested from the primary author, but could not be obtained. Time interval outcome data are displayed in Table 4. All time intervals were reported as medians and therefore weighted means could not be calculated. The relative effect of direct transport to primary PCI on symptom

\begin{tabular}{|c|c|c|c|c|c|c|}
\hline Study & Design & $\begin{array}{l}\text { Intervention } \\
\text { group }\end{array}$ & Control group & Participants & $\begin{array}{c}\text { EMS } \\
\text { provider type }\end{array}$ & $\begin{array}{l}\text { Relevant outcome } \\
\text { data reported }\end{array}$ \\
\hline Armstrong ${ }^{26}$ & RCT & $\begin{array}{l}\text { Direct transport } \\
\text { from scene to } \\
\text { PCl with } \\
\text { clopidogrel } 300 \\
\text { mg }\end{array}$ & $\begin{array}{l}\text { PH fibrinolysis } \\
\text { with TNK } \\
\text { followed by } \\
\text { transport to } \\
\text { closest ED }\end{array}$ & $\begin{array}{l}n=200 \\
\text { Age, median (IQR) = IG: } 60 \text { (49-71); } \\
\text { CG: } 58 \text { (51-69) } \\
\% \text { male = IG: 82; CG: } 75 \\
\% \text { anterior MI = IG: 42; CG: } 42 \\
\text { Exclusions = PCl available within } 1 \mathrm{~h} \\
\text { of diagnosis, Cls to fibrinolysis, prior } \\
\text { CABG, GP antagonist within } 7 \mathrm{~d}\end{array}$ & $\begin{array}{c}\text { Not } \\
\text { stated }\end{array}$ & $\begin{array}{l}\text { Symptom onset to } \\
\text { intervention time } \\
\text { interval, medical } \\
\text { contact to } \\
\text { intervention time } \\
\text { interval }\end{array}$ \\
\hline $\begin{array}{l}\text { Le May } \\
\text { et al. }{ }^{27}\end{array}$ & $\begin{array}{l}\text { Prospective } \\
\text { observational } \\
\text { cohort with } \\
\text { historical } \\
\text { control group }\end{array}$ & $\begin{array}{l}\text { Direct } \\
\text { transport from } \\
\text { scene to } \mathrm{PCl}\end{array}$ & $\begin{array}{l}\text { - Historical } \\
\text { controls } \\
\text { - Transport to } \\
\text { closest ED }\end{array}$ & $\begin{array}{l}n=333 \\
\text { Mean age (SD) = IG: } 64.3(14) ; \\
\text { CG: } 64.5 \text { (14.5) } \\
\% \text { male = IG: 70.4; CG: } 66.2 \\
\% \text { anterior MI = IG: 44.4; CG: } 46.0 \\
\text { Exclusions = VSA, hemodynamic } \\
\text { instability, LBBB }\end{array}$ & Paramedic & $\begin{array}{l}\text { All-cause mortality } \\
\text { (in-hospital), } \\
\text { composite outcome } \\
\text { (death or stroke), } \\
\text { stroke (at } \\
\text { unspecified time } \\
\text { point) }\end{array}$ \\
\hline $\begin{array}{l}\text { Thiele } \\
\text { et al. }^{29}\end{array}$ & $\mathrm{RCT}$ & $\begin{array}{l}\mathrm{PH} 1 / 2 \text { dose } \\
\text { fibrinolysis with } \\
\text { reteplase, } \\
\text { abciximab, } \\
\text { direct transport } \\
\text { from scene to } \\
\mathrm{PCl}\end{array}$ & $\begin{array}{l}\mathrm{PH} 1 / 2 \text { dose } \\
\text { fibrinolysis } \\
\text { with reteplase, } \\
\text { abciximab, and } \\
\text { transport to ED }\end{array}$ & $\begin{array}{l}n=164 \\
\text { Median age, yr (IQR) = IG: } 65 \text { (57-72); } \\
\text { CG: } 60 \text { (52-69) } \\
\% \text { male = IG: 74; CG: } 78 \\
\% \text { anterior MI = IG: 46; CG: } 50 \\
\text { Exclusions = Cls to fibrinolysis }\end{array}$ & MD & $\begin{array}{l}\text { All-cause mortality } \\
\text { ( } 30 \mathrm{~d}, 6 \mathrm{mo} \text { ), } \\
\text { composite (death, } \\
\text { reinfarction, stroke) } \\
\text { (30 d, } 6 \text { mo), } \\
\text { on-scene time }\end{array}$ \\
\hline $\begin{array}{l}\text { Terkelsen } \\
\text { et al. } .^{28}\end{array}$ & $\begin{array}{l}\text { - Prospective } \\
\text { observational } \\
\text { cohort with } \\
\text { concurrent } \\
\text { control group } \\
\text { - Allocation } \\
\text { determined } \\
\text { by availability } \\
\text { of MD for } \\
\text { transport }\end{array}$ & $\begin{array}{l}\text { Direct transport } \\
\text { from scene to } \\
\mathrm{PCl} \text { (only if MD } \\
\text { present) }\end{array}$ & $\begin{array}{l}\text { - Transport to } \\
\text { closest ED } \\
\text { then inter- } \\
\text { hospital } \\
\text { transfer for } \\
\text { PCl } \\
\text { - No prehospital } \\
\text { diagnosis }\end{array}$ & $\begin{array}{l}n=106 \\
\text { Median age, yr (IQR) = IG: } 63 \text { (54-71); } \\
\text { CG: } 67 \text { (56-75) } \\
\% \text { male = IG: } 90 ; \text { CG: } 65 \\
\% \text { anterior MI = IG: } 33 ; \text { CG: } 40 \\
\text { Exclusions = PCI physician did not } \\
\text { confirm STEMI, > } 12 \text { h symptoms, } \\
\text { walk-in patients, unconscious on arrival }\end{array}$ & $\begin{array}{l}\text { MD or } \\
\text { ambulance } \\
\text { personnel }\end{array}$ & $\begin{array}{l}\text { In-hospital mortality, } \\
\text { symptom onset to } \\
\text { intervention, on } \\
\text { scene time }\end{array}$ \\
\hline $\begin{array}{l}\text { van Bavel } \\
\text { et al. } .^{30}\end{array}$ & $\begin{array}{l}\text { - Prospective } \\
\text { observational } \\
\text { study with } \\
\text { concurrent } \\
\text { control group } \\
\text { - Allocation } \\
\text { determined } \\
\text { by degree of } \\
\text { STE on ECG }\end{array}$ & $\begin{array}{l}\text { Direct transport } \\
\text { from scene to } \\
\mathrm{PCl}\end{array}$ & $\begin{array}{l}\text { PH fibrinolysis } \\
\text { followed by } \\
\text { transport to } \\
\text { closest ED }\end{array}$ & $\begin{array}{l}n=177 \\
\text { Age, yr = unknown statistic IG: } 60.7 ; \\
\text { CG: } 65 \\
\% \text { male = IG: } 77 ; \text { CG: } 73 \\
\% \text { anterior MI = IG: } 57 ; \text { CG: } 24 \\
\text { Exclusions = not reported }\end{array}$ & $\begin{array}{l}\text { MD and } \\
\text { RN }\end{array}$ & $\begin{array}{l}\text { All-cause mortality } \\
\text { ( } 24 \mathrm{~h}, 30 \mathrm{~d}, 1 \mathrm{yr}) \text {, } \\
\text { composite outcome } \\
\text { (death, reinfarction, } \\
\text { stroke, need for } \\
\text { revascularization) } \\
\text { ( } 30 \mathrm{~d}, 1 \mathrm{yr} \text { ) }\end{array}$ \\
\hline
\end{tabular}


onset-to-intervention interval was highly dependent on the nature of the comparison strategy. For example, Armstrong $^{26}$ reported a 49-minute additional delay in median symptom onset-to-intervention time when the compari- son was prehospital fibrinolysis. In contrast, Terkelsen and colleagues $^{28}$ reported a reduction of 46 minutes when the comparison was between transportation to the local hospital followed by interhospital transfer for primary PCI.

\begin{tabular}{|c|c|c|c|c|c|c|}
\hline Study & Design & Selection bias & Allocation bias & $\begin{array}{l}\text { Baseline } \\
\text { confounder }\end{array}$ & Blinding & Follow-up rate \\
\hline Armstrong $^{26}$ & $\mathrm{RCT}$ & Weak* & Moderate† & Strong $\ddagger$ & Strong & Strong \\
\hline Thiele et al. ${ }^{29}$ & $\mathrm{RCT}$ & Weak & Strong & Strong & Strong & Strong \\
\hline Terkelsen et al. ${ }^{28}$ & Observational & Moderate & Weak & Weak & Weak & Strong \\
\hline van Bavel et al. ${ }^{30}$ & Observational & Weak & Weak & Weak & Weak & Strong \\
\hline Le May et al. ${ }^{27}$ & Observational & Moderate & Moderate & Strong & Weak & Strong \\
\hline \multicolumn{7}{|c|}{$\begin{array}{l}\text { RCT = randomized controlled trial. } \\
\text { *Poor quality methodology and high risk of bias. } \\
\text { † Moderate quality methodology and moderate risk of bias. } \\
\text { ₹Strong quality methodology and low risk of bias. }\end{array}$} \\
\hline
\end{tabular}

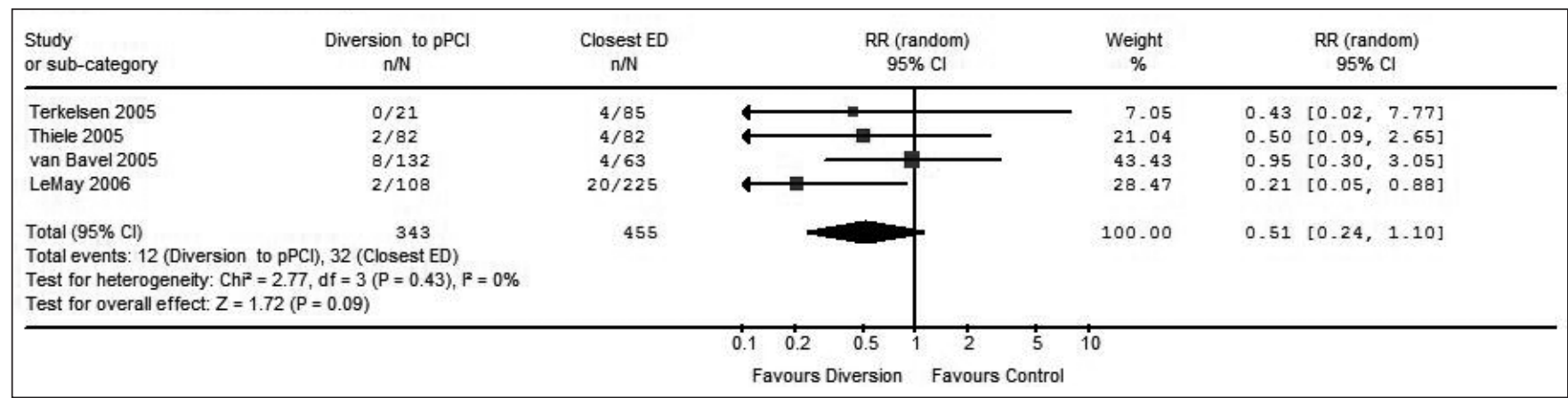

Fig. 2. Short-term mortality comparison between those diverted to primary percutaneous coronary intervention (pPCl) and those transported to the closest emergency department (ED). The short-term mortality (30 d or in-hospital) in patients diverted directly to primary $\mathrm{PCl}$ by emergency medical services personnel as compared with those transported to the closest hospital for initial treatment is shown. The relative risk (RR) generated from individual studies (squares) and 95\% confidence intervals (Cls) (horizontal lines) are plotted. The diamond represents the pooled $\mathrm{RR}$ and $95 \% \mathrm{Cl}$ generated with a random effects model. When the horizontal bars or the diamond cross 1, the effect of direct transport to primary $\mathrm{PCl}$ is not statistically different from transportation to the closest hospital. $\mathrm{n}=$ number of deaths, $\mathrm{N}=$ total number of patients in group.

Table 4. Median time interval data from the 5 included studies

\begin{tabular}{|c|c|c|c|c|c|c|}
\hline \multirow[b]{3}{*}{ Study } & \multicolumn{6}{|c|}{ Time interval, min (IQR) } \\
\hline & \multicolumn{2}{|c|}{ Symptom onset to intervention } & \multicolumn{2}{|c|}{ On scene } & \multicolumn{2}{|c|}{ Medical contact to intervention } \\
\hline & Direct to $\mathrm{PCl}$ & Closest ED & Direct to $\mathrm{PCl}$ & Closest ED & Direct to $\mathrm{PCl}$ & Closest ED \\
\hline Armstrong $^{26}$ & $\begin{array}{c}140 \text { (115-171) } \\
\text { PCl start }\end{array}$ & $\begin{array}{c}91(70-156) \\
\mathrm{PH} \text { fibrinolysis }\end{array}$ & NR & NR & $\begin{array}{c}104(88-126) \\
\text { ambulance } \\
\text { arrival to } \mathrm{PCl}\end{array}$ & $\begin{array}{c}46 \text { (35-55) } \\
\text { ambulance } \\
\text { arrival to } \\
\text { fibrinolysis }\end{array}$ \\
\hline Thiele et al. ${ }^{29}$ & $140(95-220)$ & NR & NR & NR & NR & NR \\
\hline Le May et al. ${ }^{27}$ & NR & NR & $43(34-52)$ & $41(35-50)$ & NR & NR \\
\hline Terkelsen et $\mathrm{al}^{28}$ & $\begin{array}{c}129 \text { (99-185) } \\
\text { PCl start }\end{array}$ & $\begin{array}{c}175(149-266) \\
\mathrm{PCl} \text { start after IH } \\
\text { transfer }\end{array}$ & $21(16-23)$ & $\begin{array}{c}13 \text { (10-17) } \\
\text { (no PH ECG) }\end{array}$ & NR & NR \\
\hline van Bavel et al. ${ }^{30}$ & NR & NR & NR & NR & NR & NR \\
\hline
\end{tabular}




\section{Subgroup analysis}

A post hoc subgroup analysis was conducted to explore the effect of control group intervention on treatment effect (Fig. 3). We grouped studies by the presence or absence of prehospital fibrinolytic use in control group patients. Among the 2 studies with prehospital fibrinolysis use in the control group, diversion to primary PCI was not associated with a statistically significant reduction in mortality, when compared with transportation to the closest hospital (pooled RR 0.77, 95\% CI 0.302.01). Among studies involving other control group strategies (e.g., transportation to the closest hospital without prehospital fibrinolysis and interhospital transfer for PCI) short-term mortality was lower with a strategy of diversion to primary PCI versus a strategy of transportation to the closest hospital (pooled RR of $0.24,95 \%$ CI $0.07-0.87$ ).

\section{DISCUSSION}

After a comprehensive systematic review of the world literature, we found that there were insufficient data derived from direct comparisons to support the effectiveness of direct transport of prehospital STEMI patients for primary PCI when compared with transportation to the closest hospital. The sparse data has been produced by 5 heterogeneous studies with major methodological flaws. With respect to contemporary North American emergency medical systems, the generalizability of the data we present in this review is limited, given that only 2 studies were from Canada. Only 1 study described prehospital 12-lead interpretation by a paramedic.

We have discovered that the enthusiasm for direct transport to primary PCI, as demonstrated by implementation in systems across North America, Europe and Australia, ${ }^{16-18,20-22}$ is not supported by any studies directly comparing strategies for STEMI patients diagnosed in the prehospital setting. The most recent Canadian report of such an implementation is from Ottawa, Ont. ${ }^{16}$ The authors compare a cohort of 135 STEMI patients who were brought directly to a PCI centre by EMS, bypassing local EDs as necessary, with a cohort of 209 patients diagnosed in community EDs and subsequently transferred to a PCI centre for primary PCI. Eighty percent of the field triage patients achieved a door-to-balloon time of less than 90 minutes. Only $11.9 \%$ of 209 patients referred from community EDs achieved a door-to-balloon time of less than 90 minutes. These findings are consistent with previous studies demonstrating the time savings associated with the prehospital diagnosis of STEMI. ${ }^{31-33}$

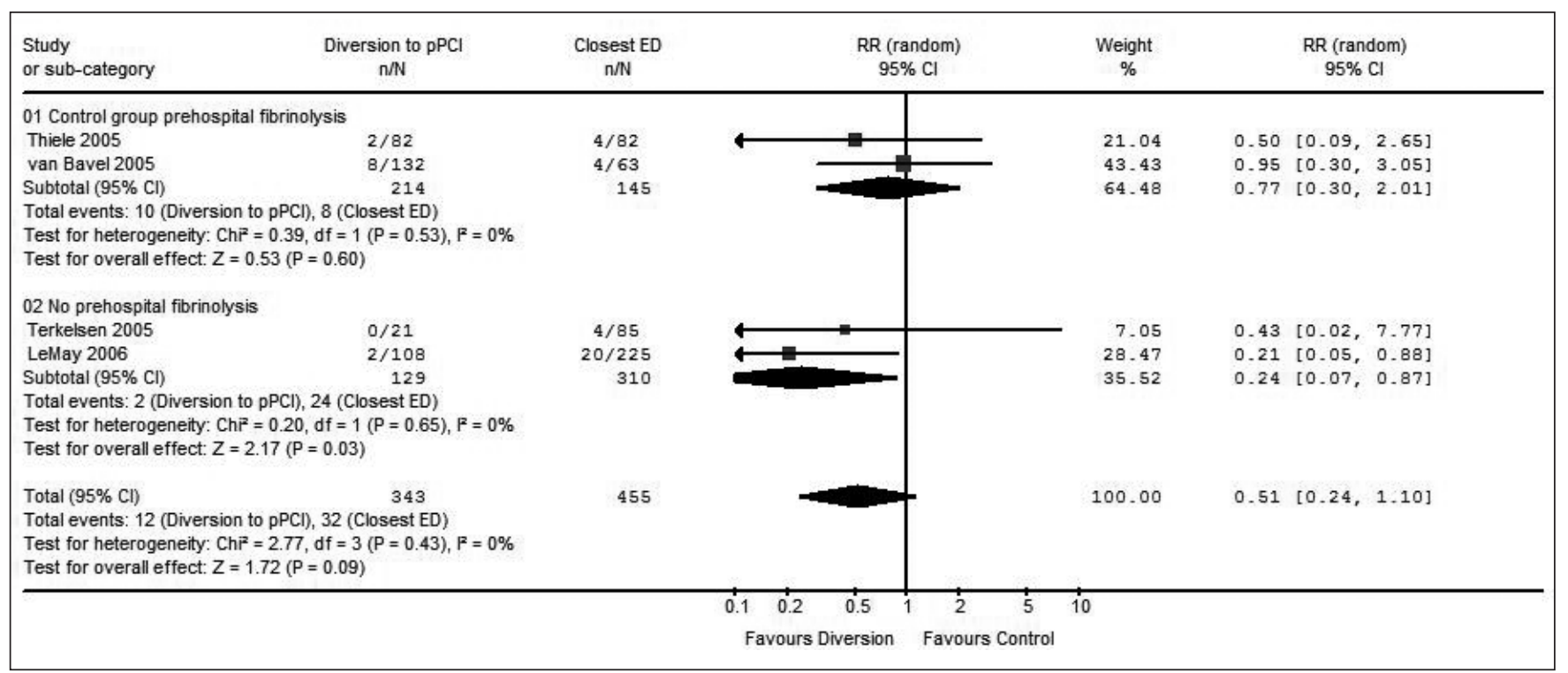

Fig. 3. Short-term mortality outcomes by control group intervention type. The short-term mortality (30 d or in-hospital) in patients diverted directly to primary percutaneous coronary intervention (pPCI) by emergency medical services personnel as compared with those transported to the closest hospital for initial treatment grouped by type of control intervention is shown. The relative risk (RR) generated from individual studies (squares) and 95\% confidence intervals (Cls) (horizontal lines) are plotted. Pooled estimates of effect (random effects model) for each subgroup and all studies are represented as diamonds. When the horizontal bars or the diamond cross 1, the effect of direct transport to primary PCl is not statistically different from transportation to the closest hospital. $E D=$ emergency department; $n=$ number of deaths, $N=$ total number of patients in group. 
Although it remains unclear whether direct transportation for primary PCI is superior to other strategies involving transportation to the closest hospital, our subgroup analysis (Fig. 3) allows us to hypothesize that direct transport for primary PCI may be superior to strategies involving transportation to the closest hospital only when prehospital fibrinolytic is not used. This is consistent with data from 2 recent French studies, including a registry and randomized controlled trial of prehospital patients with STEMI, which have also cast doubt on the superiority of PCI over prehospital fibrinolysis in certain settings. ${ }^{34,35}$

There are 2 time variables that are hypothesized to be important in determining the optimal reperfusion strategy for any given patient with STEMI: 1) time from symptom onset to reperfusion decision and 2) the "delta" time. The delta is the theoretical time interval between when the patient could receive a fibrinolytic and when the patient could have a PCI balloon inflated across the culprit coronary lesion.

With regard to the time from symptom onset to reperfusion decision interval, there is a hypothesis based on several post hoc subgroup analyses from previous studies that primary PCI may not be superior to fibrinolysis in patients who present very early after the onset of symptoms (e.g., $<2-3$ h). ${ }^{9,36,37}$ The time data in Table 4 shows that at least 3 of 5 studies (2 did not report) contained a significant number of patients who presented early based on median symptom onset-to-intervention time intervals, but this group of patients was not reported separately.

With regard to the second time variable (i.e., the delta) it remains unclear when the physiologic advantage of primary PCI over fibrinolysis with respect to mortality, reinfarction and stroke is offset by the associated additional delay to reperfusion. In the CAPTIM trial, ${ }^{35}$ in which STEMI patients were randomly assigned in the prehospital setting to receive primary PCI or prehospital fibrinolysis, primary PCI caused greater delay between symptom onset to reperfusion (i.e., a median delay of $190 \mathrm{~min}$ for PCI v. $130 \mathrm{~min}$ for prehospital fibrinolysis) and no clinical advantage was observed with respect to a combined end point of death, reinfarction and stroke at 30 days $(6.2 \%$ for primary PCI v. $8.2 \%$ for prehospital fibrinolysis, $p=0.29)$. CAPTIM was excluded from this review because both arms of the trial involved direct transport to specialized cardiac care centres with primary PCI facilities. Pinto and colleagues ${ }^{38}$ report data from the National Registry of Myocardial Infarction from 1994 to 2003 for 192509
STEMI patients admitted to hospital. They analyzed the association between the delta at the level of the hospital (median door-to-balloon interval minus median door-to-needle interval), and the clinical outcome. Inhospital mortality increased $10 \%$ with every 30 -minute increase in the delta. The adjusted mortality was identical for fibrinolytic therapy and primary PCI when the delta was 114 minutes (95\% CI 96-132 min). In contrast, data from the Swedish RIKS-HIA registry ${ }^{39}$ on 26205 consecutive STEMI patients, suggest that even in early presenters ( $<2 \mathrm{~h}$ symptom duration) the superior strategy is primary PCI, as long as the delta is less than 4 hours. Unfortunately, the data from studies included in this review did not allow for a detailed exploration of the relationship between the relative benefit of the prehospital strategies and these key time intervals.

Although there have been many studies comparing immediate fibrinolysis to primary PCI in admitted patients, ${ }^{8}$ we have identified a paucity of prehospital data. This has resulted in data being extrapolated from hospital to the prehospital setting in the creation of guidelines and national initiatives. ${ }^{14,15,10}$ There are several reasons why this may be misleading. Compared with patients who self-transport to the ED, patients who call EMS with acute coronary syndrome tend to have had a shorter duration of symptoms before seeking medical care, and are more likely to have a previous history of cardiac disease. They are older, more likely to be female and receive more aggressive management when they reach the hospital. ${ }^{40}$ There are many feasibility and safety issues that are unique to the management of STEMI patients in the prehospital setting. These include the diagnostic ability of prehospital providers, the ability to safely administer prehospital fibrinolysis, potential transport delays associated with diversion to a PCI centre, and the ability of a system to effectively activate PCI resources from the prehospital setting.

Prehospital data should be sought before we implement costly large-scale regionalization projects and STEMI "systems of care," which include direct transport for primary PCI. There are certainly sound arguments to pursue further research on direct transportation for primary PCI as a potential strategy for Canadian prehospital STEMI patients for several reasons: current medical contact-to-balloon times in North America are unacceptably long, ${ }^{38,41,42}$ there is a clear relationship between reperfusion delay and mortality, ${ }^{41,42}$ improved outcomes have been demonstrated in patients transferred from community hospitals to PCI centres for primary PCI when compared with 
in-hospital fibrinolysis ${ }^{7,9}$ and prehospital fibrinolysis is not available in most North American EMS systems. Future trial design should incorporate specific analyses of patients who present within 2-3 hours of symptom onset and explore whether clinical characteristics such as age and infarct location should influence the choice of reperfusion strategy for the prehospital STEMI patient.

\section{Limitations}

Our study has several limitations. We excluded abstractonly reports and may have missed some relevant data. Second, the missing data from the Armstrong (WEST) trial ${ }^{26}$ represents $10 \%$ of the patients included in the final review and would have allowed for more meaningful pooled estimates. A formal analysis for publication bias was not conducted, because we found no statistically significant effect on our primary outcome, making the calculation of a fail-safe number nonsensical, and there were too few studies to compose a useful funnel plot. We make the conservative assumption that a number of small negative unpublished trials were missed, and our results may be biased toward showing a more positive effect than truly exists.

The studies included in this review had significant potential for bias, and, thus, the results of the metaanalysis have been interpreted with caution. Particular to the studies included in this review, the issue of allocation bias is significant. Several studies did not adequately report important operational details, such as the process of catheterization laboratory activation, making it difficult to compare studies and determine the generalizability of their findings.

We made a post hoc decision to change our primary outcome to a composite of in-hospital or 30-day mortality because few studies reported 30-day mortality. In-hospital mortality was expected to closely estimate 30 -day mortality and, accordingly, this change was expected to have little impact on our final conclusions.

Because of the nature of prehospital care, the relative benefit of diversion to primary PCI versus transportation to the closest hospital is very likely to be dependent on a host of particular local variables, such as geography, the relative distribution of hospitals within a region, EMS system configuration and the quality of STEMI management at each of the local hospitals. The results from any investigation exploring this issue need to be considered carefully in the context of local conditions.

\section{CONCLUSION}

There is insufficient evidence to support the effectiveness of direct transport for primary PCI when compared with transportation to the closest hospital in patients with STEMI. Further research is needed to determine the optimal prehospital strategy for STEMI patients. There should be a focus on the use of prehospital fibrinolysis as an alternative strategy to direct transport for PCI. Future studies should also address the impact of symptom duration on the relative treatment effect of one reperfusion strategy over the other.

Acknowledgements: We would like to thank Devin Hart, Suzanne Chung, Olga Serebrennick, Matthew Common and Jessica Common for assistance with blinding articles. We acknowledge Cathal O'Donnell for his contributions to the manuscript, and we thank Goldie Louie and Henry Lam of the Sunnybrook Health Sciences Centre Library for their assistance in locating articles. We would also like to thank Eugene Crystal, Freddy Lippert, Cathy Longley, Akira Nishisaki, Thomas Novak, Ayelet Rimon, Valeria Rac, Anna Trompeo, Cathy Zahn and all of the volunteer translators who assisted us with interpreting the non-English articles.

Competing interests: Dr. Morrison has participated in several industry-funded trials on the topic of acute coronary syndrome as site collaborator. Sponsors have included AstraZeneca, Ely Lilly, Boehringer Ingelheim and Genetech. She currently is a coinvestigator on a peer-reviewed study cofunded by the Canadian Institute of Health Research and Hoffman Laroche addressing transfer for PCI after community fibrinolysis. Dr. Arntz has participated in several industry-funded trials on the topic of acute coronary syndrome. Sponsors have included Bristol-Myers Squibb Germany, Boehringer Ingelheim, and Sanofi-Aventis.

\section{REFERENCES}

1. Table 1: Ten leading causes of death, Canada, 2004 and 2005. Ottawa (ON): Statistics Canada; 2009. Available: www.stat can.gc.ca/pub/84-215-x/2009000/tbl/tbl1-eng.htm (accessed 2009 Jul 28).

2. Cardiovascular disease mortality surveillance information; Ottawa (ON): Public Health Agency of Canada, Ottawa (ON): Public Health Agency of Canada; 2008. Available: www.phac -aspc.gc.ca/cd-mc/cvd-mcv/cvd_mortality-mcv_mortalite -eng.php\#cvdmtb (accessed 2009 Jul 28).

3. Access to urgent PCI for ST segment elevation myocardial infarction. Final report and recommendations. Toronto (ON): Cardiac Care Network of Ontario; 2004. p. 1-194.

4. McGinn AP, Rosamond W, Goff D, et al. Trends in prehospital delay time and use of emergency medical services for acute myocardial infarction: experience in 4 US communities from 1987-2000. Am Heart J 2005;150:392-400. 
5. Steg PG, Danchin N. WEST: new data on the integration of early thrombolysis and mechanical intervention in the early management of STEMI. Eur Heart J 2006;27:1511-2.

6. Travers A. Achieving optimal care for ST-segment elevation myocardial infarction in Canada. CMAJ 2007;176:1843-4.

7. Andersen HR, Nielsen T, Rasmussen D, et al. A comparison of coronary angioplasty with fibrinolytic therapy in acute myocardial infarction. N Engl 7 Med 2003;349:733-42.

8. Keeley EC, Boura JA, Grines CL. Primary angioplasty versus intravenous thrombolytic therapy for acute myocardial infarction: a quantitative review of 23 randomized trials. Lancet 2003;361:13-20.

9. Widimsky P, Budesinsky T, Vorac D, et al. Long distance transport for primary angioplasty vs immediate thrombolysis in acute myocardial infarction: final results of the randomized national multicentre trial - PRAGUE-2. Eur Heart 7 2003;24:94-104.

10. Jacobs AK, Antman EM, Faxon DP, et al. Development of systems of care for ST-elevation myocardial infarction patients: executive summary. Circulation 2007;116:217-30.

11. Labinaz M, Swabey T, Watson R, et al. Delivery of primary percutaneous coronary intervention for the management of ST segment elevated myocardial infarction: summary of the Cardiac Care Network of Ontario Consensus Report. Can 7 Cardiol 2006;22:243-50.

12. Antman EM, Hand M, Armstrong PW, et al. 2007 focused update of the ACC/AHA 2004 guidelines for the management of patients with ST-elevation myocardial infarction: a report of the American College of Cardiology/American Heart Association Task Force on Practice Guidelines: developed in collaboration with the Canadian Cardiovascular Society endorsed by the American Academy of Family Physicians: 2007 Writing Group to Review New Evidence and Update the ACC/AHA 2004 Guidelines for the management of patients with ST-elevation myocardial infarction, writing on behalf of the 2004 Writing Committee. Circulation 2008;117:296-329.

13. Nallamothu BK, Bates ER, Herrin J, et al. Times to treatment in transfer patients undergoing primary percutaneous coronary intervention in the United States: National Registry of Myocardial Infarction (NRMI)-3/4 Analysis. Circulation 2005;111:761-7.

14. 2005 International consensus on cardiopulmonary resuscitation and emergency cardiovascular care with treatment recommendations. Circulation 2005;112:III-1-136.

15. 2005 American Heart Association guidelines for cardiopulmonary resuscitation and emergency cardiovascular care. Circulation 2005;112:IV1-203.

16. Le May MR, So DY, Dionne R, et al. A citywide protocol for primary PCI in ST-segment elevation myocardial infarction. N Engl J Med 2008;358:231-40.

17. Amit G, Cafri C, Gilutz H, et al. Benefit of direct ambulance to coronary care unit admission of acute myocardial infarction patients undergoing primary percutaneous intervention. Int $\mathrm{J}$ Cardiol 2007;119:355-8.

18. Carstensen S, Nelson GCI, Hansen PS, et al. Field triage to primary angioplasty combined with emergency department bypass reduces treatment delays and is associated with improved outcome. Eur Heart 7 2007;28:2313-9.

19. de Villiers JS, Anderson T, McMeekin JD, et al.; Foothills Interventional Cardiology Service and the Calgary STEMI QIHI group. Expedited transfer for primary percutaneous coronary intervention: a program evaluation. CMAJ 2007; $176: 1833-8$

20. Gachoud D, Wenaweser P, Laskine M, et al. Safety and outcome of patients with an acute ST-elevation myocardial infarction transferred for primary coronary intervention: the Neuchatel experience. Swiss Med Wkly 2006;136:703-8.

21. Gross BW, Dauterman KW, Moran MG, et al. An approach to shorten time to infarct artery patency in patients with STsegment elevation myocardial infarction. Am 7 Cardiol 2007; 99:1360-3.

22. Liem SS, van der Hoeven BL, Oemrawsingh PV, et al.; MISSION! Optimization of acute and chronic care for patients with acute myocardial infarction. Am Heart 72007;153:14.e1-14.e11.

23. Stroup DF, Berlin J, Morton S, et al. Meta-analysis of observational studies in epidemiology: a proposal for reporting. JAMA 2000;283:2008-12.

24. Cochrane Prehospital and Emergency Health Field Advisory Board. Prehospital search strategy terms. Melbourne (Australia): The Board; 2009. Available: www.cochranepehf.org/content .php?content.39 (accessed 2009 Jul 28).

25. Thomas BH, Ciliska D, Dobbins M, et al. A process for systematically reviewing the literature: providing the research evidence for public health nursing interventions. Worldviews Evid Based Nurs 2004;1:176-84.

26. Armstrong PW. FASTTRACK: a comparison of pharmacologic therapy with/without timely coronary intervention vs. primary percutaneous intervention early after ST-elevation myocardial infarction: The WEST (Which Early ST-elevation myocardial infarction Therapy) study. Eur Heart 7 2006;27: $1530-8$.

27. Le May MR, Davies RF, Dionne R, et al. Comparison of early mortality of paramedic-diagnosed ST-segment elevation myocardial infarction with immediate transport to a designated primary percutaneous coronary intervention center to that of similar patients transported to the nearest hospital. Am 7 Cardiol 2006;98:1329-33.

28. Terkelsen CJ, Lassen JF, Norgaard BL, et al. Reduction of treatment delay in patients with ST-elevation myocardial infarction: impact of pre-hospital diagnosis and direct referral to primary percutaneous coronary intervention. Eur Heart 7 2005;26:770-7.

29. Thiele H, Engelmann L, Elsner K, et al. Comparison of pre-hospital combination-fibrinolysis plus conventional care with pre-hospital combination-fibrinolysis plus facilitated 
percutaneous coronary intervention in acute myocardial infarction. Eur Heart J 2005;26:1956-63.

30. van Bavel H, Brenninkmeijer V, Van Ekelen $W$, et al. Regional implementation of the NVVC guideline on STelevation myocardial infarction: Report from the task force prehospital triage zuidoost erabant (PHT Z0B). Neth Heart 7 2005;13:401-7.

31. Brooks S. What is the safety, efficacy, and feasibility of PHECG and ED advance notification vs standard EMS care or vs $\mathrm{PH}$ fibrinolytics in prehospital and emergency department management of ACS and AMI? Circulation 2005;112(suppl I): III-1-136.

32. Curtis JP, Portnay E, Wang Y, et al. The pre-hospital electrocardiogram and time to reperfusion in patients with acute myocardial infarction, 2000-2002: findings from the National Registry of Myocardial Infarction-4. 7 Am Coll Cardiol 2006;47:1544-52.

33. Morrison LJ, Verbeek PR, McDonald AC, et al. Mortality and prehospital thrombolysis for acute myocardial infarction: a meta-analysis. JAMA 2000;283:2686-92.

34. Danchin N, Blanchard D, Steg G, et al. Impact of prehospital thrombolysis for acute myocardial infarction on 1-year outcome. Circulation 2004;110:1909-15.

35. Bonnefoy E, Lapostolle F, Leizorovicz A, et al. Primary angioplasty versus prehospital fibrinolysis in acute myocardial infarction: a randomised study. Lancet 2002;360:825-9.

36. Steg PG, Bonnefoy E, Chabaud S, et al. Impact of time to treatment on mortality after prehospital fibrinolysis or primary angioplasty: data from the CAPTIM randomized clinical trial. Circulation 2003;108:2851-6.

37. Zahn R, Schiele R, Gitt AK, et al. Impact of prehospital delay on mortality in patients with acute myocardial infarction treated with primary angioplasty and intravenous thrombolysis. Am Heart 7 2001;142:105-11.

38. Pinto DS, Kirtane A, Nallamothu B, et al. Hospital delays in reperfusion for ST-Elevation myocardial infarction. Circulation 2006;114:2019-25.

39. Stenestrand U, Lindback J, Wallentin L; RIKS-HIA Registry. Long-term outcome of primary percutaneous coronary intervention vs prehospital and in-hospital thrombolysis for patients with ST-elevation myocardial infarction. JAMA 2006;296:1749-56.

40. Canto JG, Zalenski RJ, Ornato JP, et al. Use of emergency medical services in acute myocardial infarction and subsequent quality of care: observations from the National Registry of Myocardial Infarction 2. Circulation 2002;106:3018-23.

41. McNamara RL, Herrin J, Wang Y, et al. Impact of delay in door-to-needle time on mortality in patients with ST-segment elevation myocardial infarction. Am J Cardiol 2007;100:1227-32.

42. McNamara RL, Wang Y, Herrin J, et al. Effect of door-toballoon time on mortality in patients with ST-segment elevation myocardial infarction. 7 Am Coll Cardiol 2006;47:2180-6.

Correspondence to: Dr. Steven Brooks, Rescu, St. Michael's Hospital, 193 Yonge St., 5th Floor, Toronto ON M5B 1M8; brooksst@smh.toronto.on.ca 